\title{
Design of Sealing Tester for Heavy Vehicle Air Brake Systems
}

\author{
Mehmet Toklucu ${ }^{1 *}$, Süleyman Neşeli ${ }^{2}$ \\ 0000-0003-4465-9651 ${ }^{1}, 0000-0001-5979-3728^{2}$ \\ ${ }^{1}$ Department of Automotive Engineering, Faculty of Technology, Selçuk University, Konya, 42100, Turkey \\ ${ }^{2}$ Department of Mechanical Engineering, Faculty of Technology, Selçuk University, Konya, 42100, Turkey
}

\begin{abstract}
Safety tests of heavy vehicle brake systems should be carried out for the safety of highways. There is a legal obligation to check whether the parts approved by the competent authorities are used in brake systems or not. For this purpose, the sealing test is generally performed to check whether the system is working effectively and efficiently or not. In this study, the sealing test is dependent on how the operator who implements the test carefully. The operator must govern the test period carefully so that the data obtained must be accurately calculated and accordingly, the test result must be evaluated by the operator. In these operations performed manually, the operator may make errors that affect the results. In this study, a micro controller card and pressure sensor is used for the computer aided testing of air brake system sealing of heavy vehicle vehicles. The aim of this study is to develop test equipment with an interface software for automatic testing of heavy vehicle infiltration. With the developed tester, the reliability of the current manual test has been significantly increased and the time spent by the operator on the test has been minimized. Considering that one million vehicles are inspected annually, a labor force saving of 4 million minutes per year has been achieved.
\end{abstract}

Keywords: Air brake, Leak test, Heavy vehicle.
* Corresponding author

Mehmet TOKLUCU

mtoklucu42@gmail.com

Adress: : Faculty of Technology, Selçuk University, Konya, Turkey

Tel:+905457262433

Researh Article

$\begin{array}{ll}\text { Manuscript } & \\ \text { Received } & 06.05 .2020 \\ \text { Revised } & 04.06 .2020 \\ \text { Accepted } & 12.06 .2020\end{array}$

Doi: 10.30939/ijastech..733221

\section{Introduction}

For the road safety in Turkey, vehicle inspection in accordance with international norms, training qualified personnel trained in international standards, reducing vehicle accidents, ensuring traffic safety, opening vehicle inspection stations for the establishment of a new standard inspection understanding were provided. "Regulation on the opening and operation of vehicle inspection stations" came into force on 01.01.2005 [1]. According to this provision, vehicles must be produced in a way that does not pose a danger to the safety of life and property and periodic inspections must be carried out.

The duties of the equipment related to braking used in vehicles are to slow the vehicle, stop it at a certain place if necessary, prevent unwanted acceleration of the vehicle during the downhill course, and prevent the self-movement of a standing vehicle [2]. High standard braking systems are required for vehicle driving safety $[3,4]$. For this purpose, there is a legal obligation to use parts that have been tested and approved by the competent authorities in the braking systems of heavy vehicles carrying passengers and cargo. The brake system needs to be checked for compliance with various tests.

In the air brake system, compressed air produced by the compressor is stored in the air tanks located on the vehicle. A vehicle brake system are consists of air filter, compressor air dryer, pressure regulators, safety valves, air tanks, brake valve, parking brake valves, brake cylinders, and pressure resistant hoses that allow them to link with each other. In order for the brake system to work properly, the sealing of each part and joint on the system is of great importance in terms of safety.

Due to the lack of studies on the sealing test system in the literature, the necessary applications were made to the Turkish skate and Trademark institution regarding the software and tester developed in this study. So, the patent process related to the test system is ongoing. In this study, a test equipment and test software were developed for the purpose of automatically determining whether the stored air 


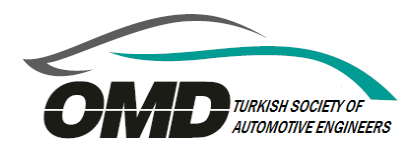

leaked or not for the heavy vehicle braking system. Thanks to the developed device and software, the requirement to follow the 4 minute test time of the operator has been eliminated by performing the current test automatically. Calculation of the data obtained during the Test process and interpretation of the result with PC software has been provided. Errors that can be made by the operator have been prevented and the reliability of the test has been improved.

\section{Method}

When the vehicle's engine is started, the compressor connected to the engine fills the air tanks until it reaches the maximum pressure (about 12 Bars) determined by the vehicle manufacturer by increasing the pressure of the air it receives from the atmosphere. Some amount of air is used during braking. When the pressure in the air tanks again drops to the minimum pressure level (about 8 bar) set by the vehicle manufacturer, the compressor starts working again and continues to fill the tanks. If the brake system is not used, it must be determined whether the compressed air stored in the system is leaking from any part or a junction point. This process is called as the heavy vehicle sealing test.

According to the relevant regulation [1], the sealing test for heavy vehicles with air brake system is done as follows. The engine of the vehicle is expected to reach the system pressure of the vehicle by starting. When the system pressure is reached, the regulator disables the compressor. The manometer is attached to the test End located on the vehicle's front axle brake bellows. System pressure is determined from the label on the vehicle. The brake pedal is pressed at half the system pressure and the pressure is fixed. One minute is expected and during this time the air in the tanks is distributed to the whole system [5].

One minute end value is read from the manometer attached to the air tank test end of the vehicle and three more minutes are expected. the value on the manometer connected to the air tank at the end of three minutes is read again. the difference in the value taken from the manometer at the end of the first minute and the fourth minute gives the amount of air leakage.

The system pressure of the vehicle is determined by the vehicle manufacturer and labeled on the vehicle. According to the legislation, the amount of air leakage should not be more than $5 \%$ of the system pressure. For example;

The system pressure determined by the vehicle manufacturer or the pressure (maximum pressure) at which the compressor is deactivated by starting the vehicle (maximum pressure) is $10 \mathrm{Bar}$,

After waiting one minute for air to dissipate into the system, the pressure from the manometer connected to the front axle is $8.3 \mathrm{Bar}$.
Suppose that the value read from the manometer connected to the front axle at the end of the three-minute test period is determined to be 7.5 Bar.

Air leakage in the system is determined as $8.3-7.5=0.8$ Bar after one and four minutes. $5 \%$ of the system pressure, which is 10 bar, is calculated as $10 \times 5 / 100=0.5$ Bar. Since the amount of air leakage is greater than $5 \%$ of the system pressure (0.8 Bar > 0.5 Bar), it is determined that the brake system is leaking.

Manual sealing test given above may cause both time loss and operator errors. The schematic representation of the system developed for the purpose of automating the current test and interpreting and concluding the obtained data with computer software is given in Figure 1.

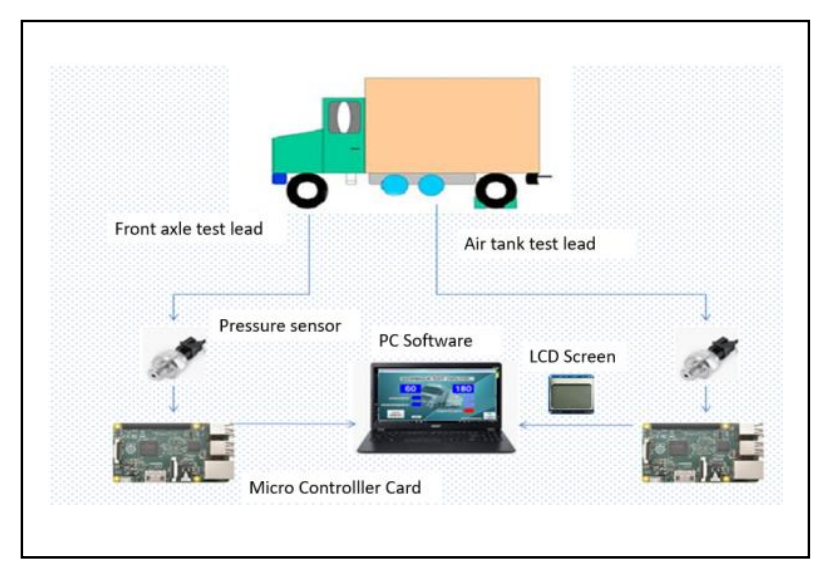

Fig. 1. Connection diagram of the leakage tester.

Two pressure sensors were used to detect the front axle pressure and air tank pressure of the Test vehicle. Two micro controller cards were used to convert the values from the pressure sensor to digital data and transfer them to the computer via the serial port. One LCD screen was used to see the front axle pressure. A 12 volt adapter was used to meet the energy requirements of the micro controller cards. The connection Jack was used for the connection of the sensor and air hoses. A software embedded in the arduino platform has been developed to interpret and conclude data from the device. The connection and product details for each element that makes up the system are given below.

\subsection{Design Of The Seal Tester}

In order to measure the pressure values of the front axle and air tank of the vehicle, the micro controller card, pressure sensor and LCD display connection have been realized. The operating range of the pressure sensor used in the study is $0-12 \mathrm{Bar}$, the measurement sensitivity is $0.02 \mathrm{Bar}$, the operating temperature range is $0-85$ degrees Celsius, the operating voltage is $5 \mathrm{~V}$, the output voltage is $0.5-4.5 \mathrm{~V}$, the response time is $2 \mathrm{Ms}$. The Arduino Uno R3, which is used as a micro controller card, has 14 Digital Input/ Output 


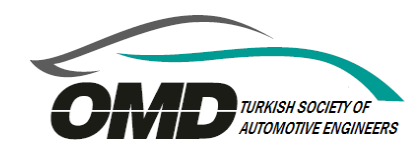

pins, 6 of which can be used as a PWM output. It also has 6 analog input pins. It has a $16 \mathrm{MHz}$ crystal oscillator, a USB connection, a power input, and a reset button. It can be powered via a USB connection or by an external power supply (2.1 mm AC - DC adapter or battery power). The power supply is selected automatically [6]. Figure 2. the analog values from the de pressure sensor are encoded into the micro controller card and converted to digital data and displayed on the LCD screen.

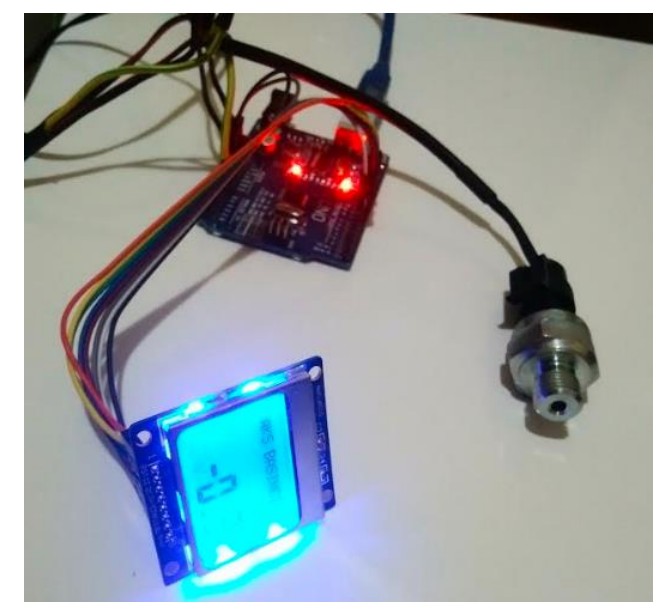

Fig. 2. Pressure sensor, LCD and micro controller card connection

The micro controller converts the analog values obtained from the pressure sensor into a digital data and allows the data to be written to the LCD screen, but also the data is transferred to the computer via the serial port.

Pressure sensor, LCD screen, micro-controller card, adapter, power switch, power socket, air input jacks and connection cables are placed in the box manufactured from laser cut Plexiglas as seen in Figure 3 and designed within the scope of this study.

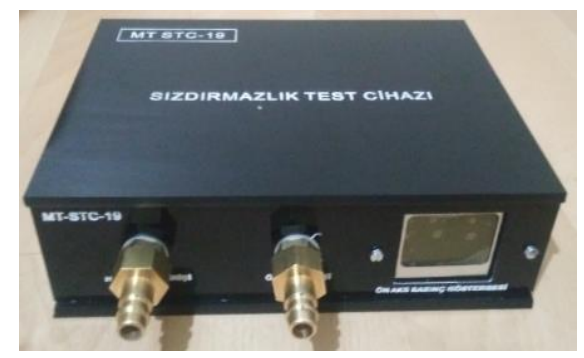

Fig. 3. Tester view

\subsection{Structure of the Tester Program}

The test program was written using the Visual Studio Net programming language to retrieve, calculate and visualize the results of data sent by the tester over the serial port.

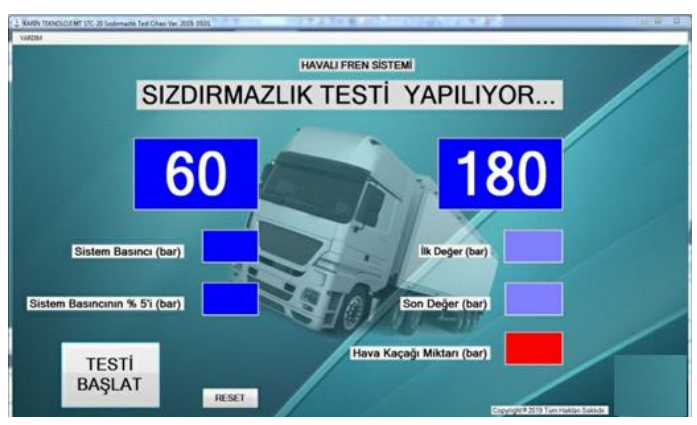

Fig. 4. Test software main screen

As shown in Figure 4, there are two countdown timers on the software main screen. $5 \%$ of system pressure and calculated system pressure are shown. A minute later, the value read from the air tank sensor is shown (First value (Bar)). At the end of three minutes, the value read from the air tank sensor is shown (last value (Bar)). There are areas where the data is printed, such as the calculated amount of leakage, and a button to start the Test (start the test).

The vehicle is operated and the air tanks are fully filled. Then, the engine is stopped and the handbrake is brought to the road position. Force is applied to the brake pedal with the apparatus seen in Figure 5. The force applied is at half of the system pressure.

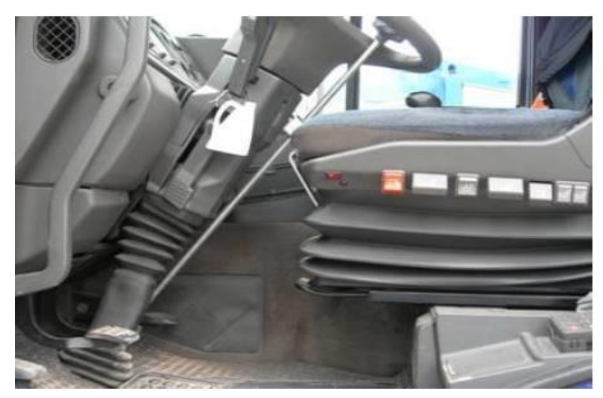

Fig. 5. Brake pedal apparatus assembly [5]

Click on the "start test" button on the software. As shown in Figure 6, the warning for entering the vehicle's system pressure by the software is displayed. To enter the system pressure, the warning screen is displayed, as shown in Figure 6. 
If the amount of leakage is more than $5 \%$ of the system

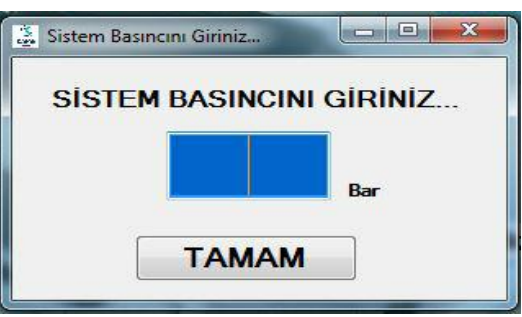

Fig. 6. System pressure data entry screen

If the system pressure is entered and the "OK" button is pressed, Figure 7 is displayed.

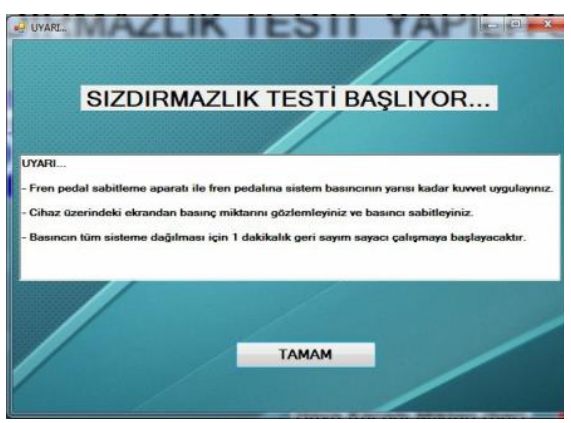

Fig. 7. Test start warning screen

The warning screen displays the steps to be taken for testing. As a result of the one-minute countdown, the value taken from the sensor connected to the air tank is recorded as "first read" and the three-minute countdown timer starts automatically. The three minutes later, the value taken from the sensor attached to the air tank is recorded as "last read". The difference between the two values read gives the amount of leakage. 5\% of the system pressure and the amount of leakage is calculated by the Program, the amount of leakage is more than $5 \%$ of the system pressure is checked. If the leakage amount is less than $5 \%$ of the system pressure, the "system is not leaking air" warning is displayed as in Figure 8.

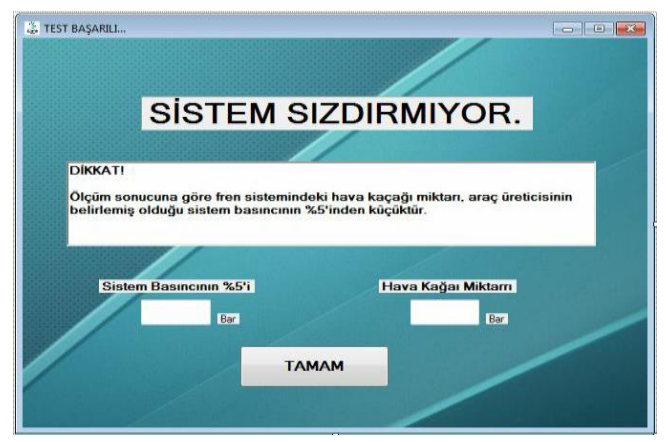
pressure, as in Figure 9, the "system is leaking air" warning will be issued.

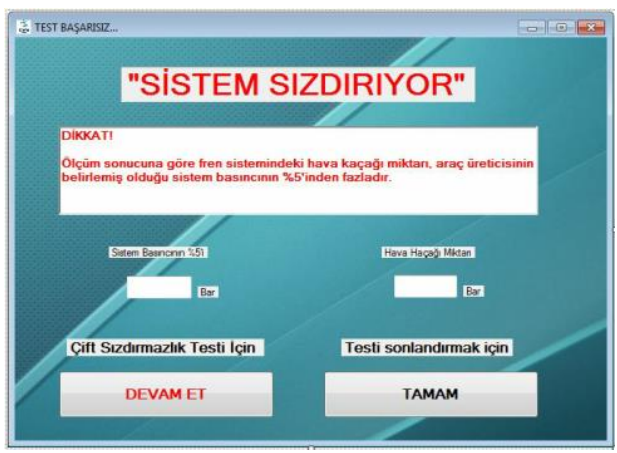

Fig. 9. Test result screen

The trailer tightness testing cannot be done alone, it must be done in conjunction with the tow vehicle. If the vehicle being tested is a trailer type vehicle, the option of whether to continue the sealing test with the double sealing test is presented by the program in Figure 9. Pressing the" Continue" button displays a warning screen, such as in Figure 10, and prompts the system pressure for the trailer (determined by the vehicle manufacturer) to be entered.

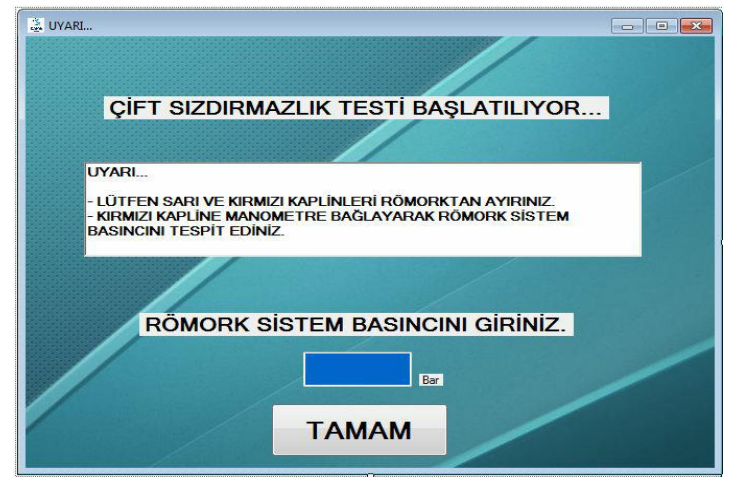

Fig. 10. Double leak test start warning screen

Trailer and tow vehicle connections are separated from each other. In Figure 11, a new test screen for double sealing testing is displayed by the program. A sealing test is performed again for the tow vehicle by the Program.

Fig. 8. Test result screen 


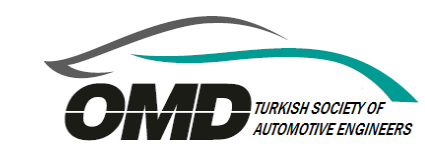

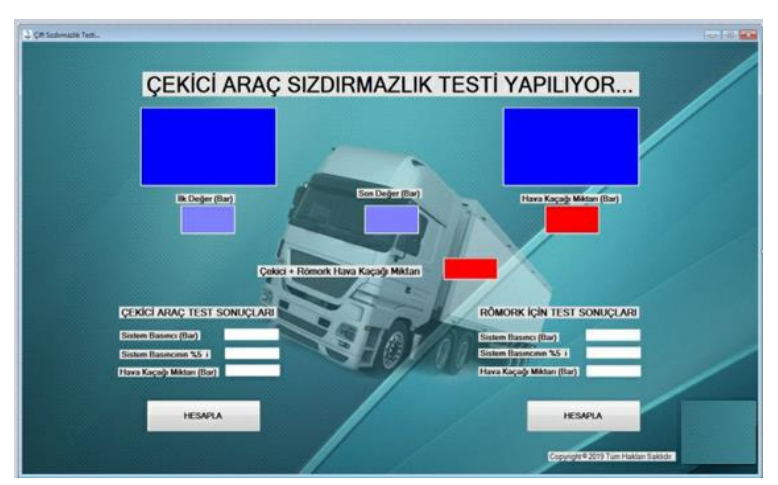

Fig. 11. Double sealing main screen

There are two countdown timers on the double sealing screen, as shown in Figure 11. The first test result is displayed in the middle of the screen as the total amount of leakage. On the left side of the screen, there are to vehicle measurement information and on the right side there are Trailer measurement information. Double sealing i.e. the sealing test for the tow vehicle is completed. From the total leak previously detected, the tow vehicle leak is subtracted. Thus, the amount of leakage of the trailer is determined. Tow vehicle and trailer, system pressure, $5 \%$ of system pressure, first and last read values and leakage quantities are calculated and displayed separately. By clicking on the "Calculate" buttons at the bottom of the screen, it is calculated whether there is an air leak on my site for the tow truck and trailer. The Program displays the calculated result. "The system leaks air" (Figure 12). "The system does not leak " (Figure 13).

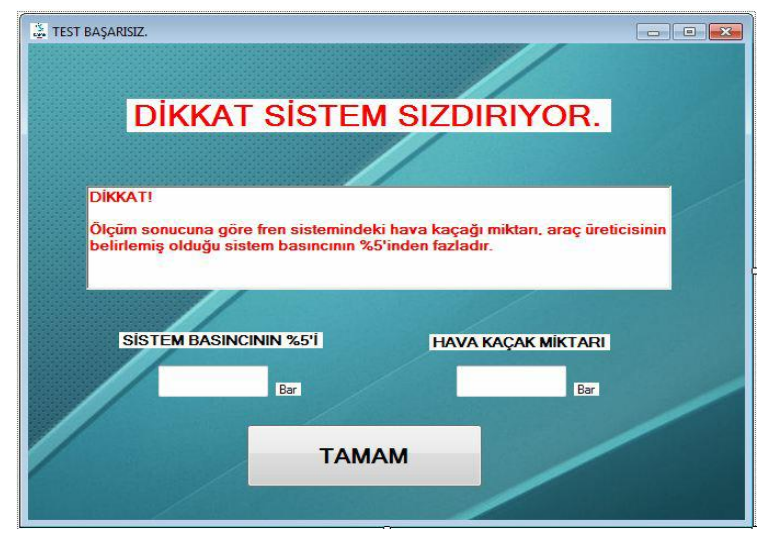

Fig. 12. "System leaking” Result screen

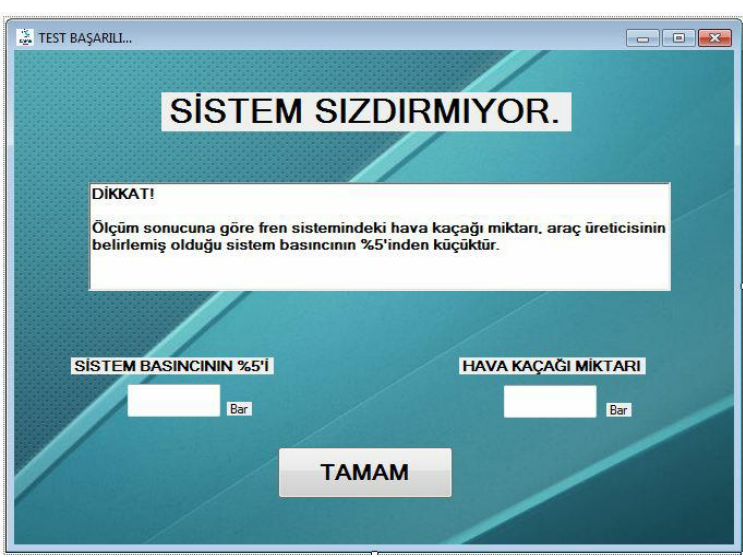

Fig. 13. "System Not Leaking" Result screen

\section{Discussion}

Sealing testing with a test equipment and its software provided many advantages. The advantage to do the work of many equipment using a single device allows us to minimize the possible errors, as well as saving the time. Elimination of the use of stopwatch and calculator, which had to be used in previous times, has eliminated the possible operation errors made by the operator. The fact that the operator did not have to measure the time allowed the technician to do other work during the 4-minute test time.

With the completion of the tester and software, sealing tests were conducted on three randomly selected heavy vehicle vehicles. The test and measurement results made by the manual method and analog manometers are given in Table 1 . The test and measurement results performed with the tester and software developed on the same tools are presented in Table 2 .

Table 1. Manual sealing test, test results.

\begin{tabular}{|l|c|c|c|c|c|c|c|}
\hline Testing & $\begin{array}{c}\text { System } \\
\text { Pressure } \\
\text { (The } \\
\text { pressure at } \\
\text { which the } \\
\text { compressor } \\
\text { is } \\
\text { deactivated) }\end{array}$ & $\begin{array}{c}\text { Pressure } \\
\text { apslied } \\
\text { to the } \\
\text { front } \\
\text { axle }\end{array}$ & $\begin{array}{c}\text { Tank } \\
\text { pressure } \\
\text { measured } \\
\text { at the } \\
\text { end of } 1 \\
\text { minute }\end{array}$ & $\begin{array}{c}\text { Tank } \\
\text { pressure } \\
\text { measured } \\
\text { at the } \\
\text { end of } 3 \\
\text { minute }\end{array}$ & $\begin{array}{c}5 \% \text { of } \\
\text { system } \\
\text { pressure }\end{array}$ & $\begin{array}{c}\text { Amount } \\
\text { of } \\
\text { leakage }\end{array}$ & Conclusion \\
\hline 1 & 9.9 & 5 & 8.8 & 8.6 & 0.49 & 0.2 & $\begin{array}{c}\text { NOT } \\
\text { LEAKING }\end{array}$ \\
\hline 2 & 11.8 & 6 & 10.1 & 10 & 0.59 & 0.1 & $\begin{array}{c}\text { NOT } \\
\text { LEAKING }\end{array}$ \\
\hline 3 & 9.7 & 5 & 8.8 & 8.1 & 0.48 & 0.7 & LEAK \\
\hline
\end{tabular}


Table 2. Results of tests with tester and software

\begin{tabular}{|c|c|c|c|c|c|c|c|}
\hline Testing & $\begin{array}{c}\text { System } \\
\text { pressure } \\
\text { (The } \\
\text { pressure at } \\
\text { which the } \\
\text { compressor } \\
\text { is } \\
\text { deactivated) }\end{array}$ & $\begin{array}{c}\text { presgure } \\
\text { applied } \\
\text { to the } \\
\text { front } \\
\text { asle }\end{array}$ & $\begin{array}{c}\text { Tenk } \\
\text { preasure } \\
\text { messured } \\
\text { at the } \\
\text { end of 1 } \\
\text { minute }\end{array}$ & $\begin{array}{c}\text { Tenk } \\
\text { pressure } \\
\text { measured } \\
\text { at the } \\
\text { end of } 3 \\
\text { minute }\end{array}$ & $\begin{array}{c}5 \% \text { of } \\
\text { system } \\
\text { pressure }\end{array}$ & $\begin{array}{c}\text { Amount } \\
\text { of } \\
\text { leakage }\end{array}$ & Conclusion \\
\hline 1 & 9.9 & 5.00 & 8.71 & 8.55 & 0.49 & 0.16 & $\begin{array}{c}\text { NOT } \\
\text { LEAKING }\end{array}$ \\
\hline 2 & 11.8 & 6.00 & 10.04 & 9.82 & 0.59 & 0.22 & $\begin{array}{c}\text { NOT } \\
\text { LEAKING }\end{array}$ \\
\hline 3 & 9.7 & 5.00 & 8.71 & 8.08 & 0.48 & 0.63 & LEAK \\
\hline
\end{tabular}

The analog manometers used in the air brake system sealing test are mostly $1 / 10$ sensitive. The precision is increased to $1 / 100$ with the designed Tester. Thus, much more precise measurement can be made.

It was concluded that the test results taken with the developed tester and software has been a good agreement with the results of of the manual tests. In manual tests, it was found that time tracking held for 1 and 3 minutes was important.

\section{Conclusions}

In this study, the design and manufacture of a sealing tester and test software for air brake systems were implemented. The pressure information obtained from the test vehicle air tank by the tester was transferred to the test software. According to the current legislation, the brake system has been determined whether there is an air leak or not by evaluating the test results via the Program. As a result of this work, a manual test, which only takes place under the control of the operator, was provided to be performed automatically. Automatic testing with the device has eliminated operator-induced errors. Thus, the operator has a chance to perform other tasks during the testing period.

More reliable results have been achieved thanks to the developed Tester and software. In our country, approximately one million heavy vehicle vehicles are tested annually. this study will save approximately 4 million minutes of time per year. When it is considered that these tests are performed in the authorized and special services besides the vehicle inspection, the savings to be gained from the time will increase even more volume. With the savings from the labour force, significant levels of added value input will be provided to the country's economy.

In this study, it was possible to perform the sealing test for the heavy vehicle braking system with a tester. In the future studies, the subjects, such as four-way safety valve Tester, ALB Tester, and the coupling breakout Tester may be the most promising topics towards developing more effectively and accurately testing systems. Moreover, with these new studies, the reliability of the tests, labor force savings, ergonomics, environmental sensitivity can be improved.

\section{Acknowledgments}

This study was carried out using the Master's Thesis titled "Design of Sealing Tester for Heavy Vehicle Air Brake Systems" at Selcuk University, Institute of Science.

\section{Nomenclature}

ALB : Load sensing valve [7]

\section{References}

[1] URL 1: E-Mevzuat (2019), Legislation Information System., https://www.mevzuat.gov.tr/Metin.Aspx?MevzuatKod=7.5.7 $182 \&$ MevzuatIliski=0\&sourceXmlSearch $=$

[2] Göktan, A.G, Ereke, M. (1995). Vehicle Brakes. İTÜ Department of Mechanical Engineering, Faculty of Technology, İstanbul.

[3] Güney, B. İ. M. (2015). Examination of brake Test standards applied in EU and USA in vehicles. Afyon Kocatepe Universty, Journal of Science and Engineering Sciences, 15, 7-16.

[4] Subramanian, S. C., Darbha, S. ve Rajagopal, K. (2006). A diagnostic system for air brakes in commercial vehicles, IEEE Transactions on Intelligent Transportation Systems, 7 (3), 360-376.

[5] Tüvtürk. (2018). SD37601 Principles of heavy vehicle inspection. Training presentation.

[6] Songül, S. (2014). Application of tank barrel stabilization system with Arduino and preparation of experimental assembly. Master Thesis, Trakya Universty, Edirne.

[7] URL 2: WABCO. (2020). Customer Center. https://www.wabco-customercentre.com/catalog/en_US /4757111150?cclcl=en_US 